\title{
Development of regional growth centres and impact on regional growth: A case study of Thailand's Northeastern region
}

This study investigates the spatial economic structure and inequality in Thailand at the national and regional levels, with a particular focus on the Northeastern region in the period from 1987 to 2007 . The study has three main points: 1) examination of the economic structure and inequality at the national level and in the Northeastern region according to the Theil index, 2) determination of regional growth centres and satellite towns by using growth pole theory as a conceptual framework and incorporating spatial interaction analysis and 3) analysis of the relationship between regional growth centres and satellite towns with regard to the impact on growth and inequality. The results show that the Northeastern region is definitely the lagging region in the nation, by both gross domestic product (GDP) and gross regional product (GRP) per capita. It was therefore selected for a case study. Spatial analysis identified Nakhon Ratchasima, Khon Kaen, Udon Thani and Ubon Ratchathani as regional growth centres. Each of them has its own sphere of influence (or satellite towns), and the total area of regional growth centres and satellite towns are classified as sub-regions. The development of regional growth centres has a direct impact on sub-regional economic growth through economic and social relationships: urbanisation, industrial development, per capita growth, the number of higher educational institutes and so on. However, such growth negatively correlates with economic equality among the provinces in a sub-region. The inequality trend is obviously on an upswing. This study suggests that industrial links between regional growth centres and their satellite towns should be improved in order for regional growth centre development to have a consistently desirable effect on both economic growth and equality. Such a strong process means that the growth of regional growth centres will spread, leading to the development of their surrounding areas.

Keywords: regional economic growth and inequality, growth pole, regional growth centres, regional decentralisation 


\section{Introduction}

Thailand is a developing country in southeast Asia (see Figure 1). It has a population of 65 million and an area of $513,120 \mathrm{~km}^{2}$. In terms of administrative divisions, it consists of seventy-six provinces and Bangkok as the capital. All of these divisions are grouped into six regions. In 1961, Thailand took the first step towards modern development by launching its first national development plan. It has promoted infrastructure development, a free-enterprise economy, pro-investment policies, export industries and spatial development for more than fifty years. Policies to decentralise the economy and reduce regional inequalities have been implemented. One of these policies is the spatial policy, which has focused on three areas: urban system development and management, regional growth centre strategy and world-region spatial development. This study focuses on the regional growth centre strategy as an engine for regional development.

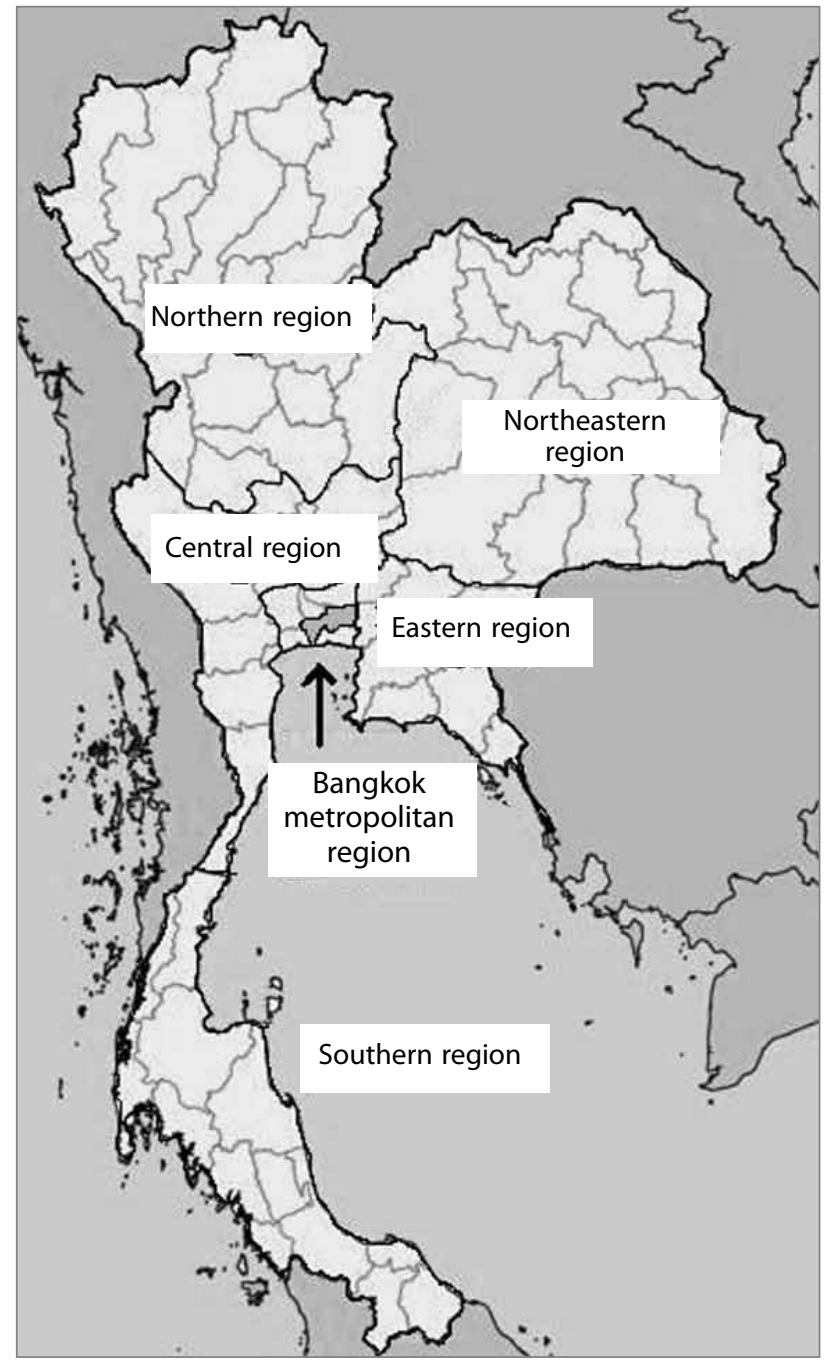

Figure 1: Map of Thailand (source: Sang-arun, 2012).
This study examines the period from 1987 to 2007 because of the availability of a constant dataset at the beginning of the study. In 2007, Thailand's gross domestic product (GDP) was THB 4.26 trillion $^{[1]}$ (about USD 0.13 trillion) and had been growing at the average rate of $5.81 \%$ for more than twenty years. This volume could be spatially divided into the gross regional product (GRP) of six regions (Northeastern, Northern, Southern, Eastern, Central and Bangkok metropolitan). The volume of the Bangkok metropolitan region is the highest, at THB 1.87 trillion ( $43.96 \%$ of GDP and about USD 0.06 trillion), with an average annual growth rate of $5.38 \%$ between 1987 and 2007; at present it also has a high per capita GRP at THB 313,979 (USD 9,812). These high values of the Bangkok metropolitan region have persisted because of the primarily urban situation of the Bangkok metropolitan region. It is not surprising that most studies of economic inequality and income distribution in Thailand (Ikemoto \& Limskul, 1987; Kaothien, 1991; Deolalikar, 2002; Tinakorn, 2002; Glassman \& Sneddon, 2003) have mentioned the disparity between the Bangkok metropolitan region (and only the Bangkok metropolitan region in some cases) and the remaining regions of the country. Figure 1 shows the map of Thailand and its regions.

Comparing the per capita GRP of each region with entire country's GDP per capita, the inequality ratio of the Northeastern region is the worst, at an average of 0.33 for 20 years (from 1987 to 2007). This means that the Northeastern region's per capita GRP is less than one-third of the GDP per capita. Certainly, the ratio of the Bangkok metropolitan region is the highest, and so it is the leading region. At the same time, the Northeastern region lags the most. Figure 2 shows the trend of the inequality ratio in per capita GRP for all regions from 1987 to 2007.

From the observation above, it is of interest to investigate the Northeastern region in greater detail regarding regional growth centres and economic development. This study explores the impact of regional growth centres on the economic growth and inequality of the Northeastern region on the following issues. First, it examines economic structure and inequality at both the national level and for the Northeastern region. Second, it determines regional growth centres and satellite towns. Finally, it analyses the relationship between regional growth centres and satellite towns with regard to the impact on growth and inequality.

\section{Theory and methodology}

The growth pole theory is usually referred to in studies about regional growth centres. It was first mention in François Perroux (1955), who stated that " $[\mathrm{g}]$ rowth does not appear eve- 


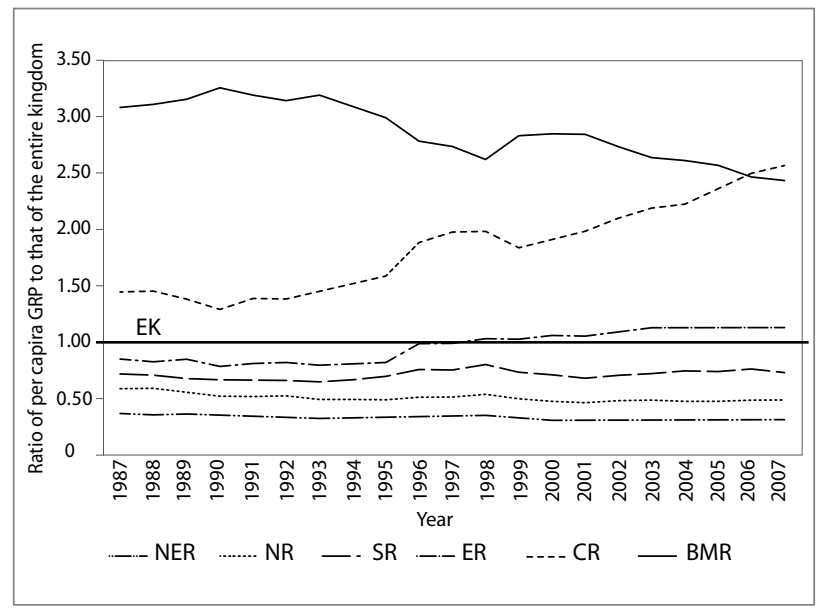

Figure 2: Ratio of per capita GRP to that of the entire country (EK = 1.0) (source: Office of the National Economic and Social Development Board, 2011).

Note: Calculated from gross domestic, regional and provincial product; NER $=$ Northeastern region, $N R=$ Northern region, $S R=$ Southern region, $\mathrm{ER}=$ Eastern region, $\mathrm{CR}=$ Central region and $\mathrm{BMR}=$ Bangkok metropolitan region, $\mathrm{EK}=$ entire kingdom.

rywhere at the same time; it becomes manifest at points or poles of growth, with variable intensity; it spreads through different channels, with variable terminal effects on the whole of the economy." For this reason, the growth pole (or core) seems to be a propulsive economic unit (Malul et al., 2012). When developments or changes occur in the pole, it will cause change in the other units as well. At that time, the pole was not involved with space, but with industrial clustering. This concept is also consistent with the "unbalanced growth" proposition of Albert O. Hirschman (1958), who took into account investment in some leading sectors, and backward and forward economic links.

Jacques Raoul Boudeville (1966) introduced the space concept in the 1960s. The spatial growth pole refers to the core area of economic agglomeration that has spread its development forces to the surrounding periphery (Darwent, 1969). It is called the growth centre, and this centre usually refers to a city or urban area. The city, as a growth pole, could lead development or growth to its periphery under two conditions. First, the city has to develop itself or make its own development forces. Second, it should spread the forces to its sphere of influence through links; these may be economic, infrastructure or even social.

In the 1970 s, growth pole theory was applied to regional development in Thailand through regional growth centre policy in four regions. The initial objectives of this policy were to develop the regional economy, to reduce regional inequalities and to

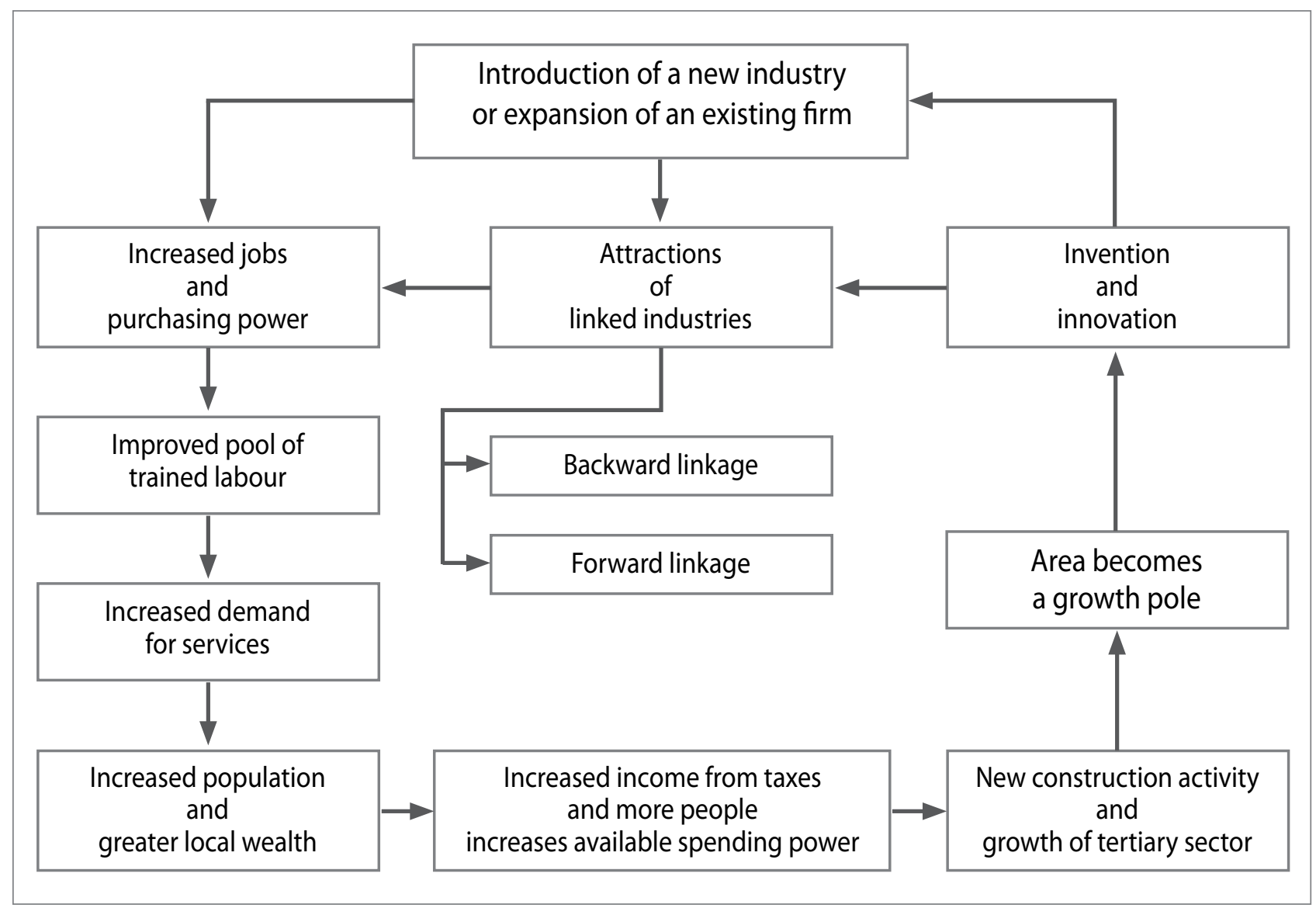

Figure 3: The growth pole's economic cumulative causation (source: Barcelona Field Studies Centre, 2011). 
restrict the over-urbanisation of the Bangkok metropolitan region. There were five primary regional growth centres: Chiang Mai in the Northern region, Songkhla in the Southern region, Chon Buri in the Eastern region, and Nakhon Ratchasima and Khon Kaen in the Northeastern region. This policy absolutely drives economic development and decentralisation, industrial development, infrastructure development, social development and regional inequality reduction. The development of new industry or economic activity in the regional growth centres encourages the concentration of further industrial activity via "cumulative causation" or a multiplier effect, as shown in Figure 3 .

The city as a growth pole is an engine for regional development, but it may cause regional inequality in cases in which the pattern of the national or regional urban system is monocentric development. More monocentricity increases inequality. Thus, a polycentric pattern of urban systems is appropriate and can also combat regional inequality (Sandberg \& Meijers, 2006). Therefore the hypothesis of this study is that development of the Northeastern region's regional growth centres causes greater regional economic growth and also reduces inequality.

\subsection{Regional growth and inequality analysis}

This study uses the following data: gross domestic product (GDP), gross regional product (GRP) and gross provincial product (GPP), as well as the population data for these levels from 1987 to 2007. The compound annual growth rate is calculated for economic growth. For regional economic inequality, a one-stage Theil decomposition method (Akita, 2000 ) is applied, as shown in Equation 1:

$$
T_{p}=\sum_{i} \sum_{j}\left(\frac{Y_{i j}}{Y}\right) \log \left(\frac{Y_{i j} / Y}{N_{i j} / N}\right)
$$

Where

$$
\begin{aligned}
& T_{P}=\text { overall economic inequality } \\
& Y_{i j}=\text { gross product of province } j \text { in region } i \\
& Y=\text { total gross product of all provinces } \\
& N_{i j}=\text { population of province } j \text { in region } i \\
& N=\text { total population of all provinces }
\end{aligned}
$$

If $T_{p i}$ is defined as follows, to measure between-province economic inequality for region $i$ as shown in Equation 2:

$$
T_{p i}=\sum_{j}\left(\frac{Y_{i j}}{Y_{i}}\right) \log \left(\frac{Y_{i j} / Y_{i}}{N_{i j} / N_{i}}\right)
$$

then the Theil index $T$ in Equation 1 can be decomposed into Equation 3:

$$
\begin{gathered}
T_{p}=\sum_{i}\left(\frac{Y_{i}}{Y}\right) T_{p i}+\sum_{i}\left(\frac{Y_{i}}{Y}\right) \log \left(\frac{Y_{i} / Y}{N_{i} / N}\right)= \\
=\sum_{i}\left(\frac{Y_{i}}{Y}\right) T_{p i}+T_{B R}= \\
=T_{W R}+T_{B R}
\end{gathered}
$$

Where

$$
\begin{aligned}
& Y_{i}=\text { total gross product of region } i \\
& N_{i}=\text { total population of region } i \\
& T_{W R}=\text { within-region economic inequality } \\
& T_{B R}=\text { between-region economic inequality }
\end{aligned}
$$

Equation 3 is the ordinary one-stage Theil inequality decomposition, in which the overall economic inequality $T_{P}$ is the sum of the within-region component $\left(T_{W R}\right)$ and the between-region component $\left(T_{B R}\right)$, where the within-region component is the weighted average of inter-province economic inequality for each region $\left(T_{p i}\right)$. The Theil index $\left(T_{p}\right)$, defined by Equation 1, employs income shares as weights. It is therefore sensitive to changes in richer provinces.

\subsection{Identification of regional growth centres}

Although there are three growth centres in the Northeastern region, as mentioned in the Sixth National Economic and Social Development Plan (1987-1991), their zones of influence (or satellite towns) are not specified. Empirical analysis is therefore required, and urban ranking is the chosen method. Provinces ${ }^{[2]}$ are the units of analysis and the variables for the ranking are shown in Table 1 . The $Z$-score regression equation is used as Equation 4:

$X=a_{1} Z_{1}+a_{2} Z_{2}+a_{3} Z_{3}+\ldots+a_{i} Z_{i}$

Where

$X=$ regional growth centre score

$a_{i}=$ weight (factor loading, computed by factor analysis of variables shown in Table 1, is used as the weight in this analysis)

$Z_{i}=Z$-score of each variable 
Regional growth centres' sphere of influence is determined by using gravity analysis to consider spatial interaction. Thus the area of each regional growth centre and its satellite towns is defined as the sub-region. The equation for the gravity analysis is shown in Equation 5:

$$
r_{i j}=\frac{\sqrt{N_{i} Y_{i}} \sqrt{N_{j} Y_{j}}}{d_{i j}^{2}}
$$

Where

$r_{i j}=$ spatial interaction of regional growth centre $i$ and satellite town $j$

$N_{i}=$ population of regional growth centre $i$

$N_{j}=$ population of satellite town $j$

$Y_{i}=\mathrm{GPP}$ of regional growth centre $i$

$Y_{j}=\mathrm{GPP}$ of satellite town $j$

$d_{i j}^{j}=$ distance between $i$ and $j$

\subsection{Impact of regional growth centre development on regional growth analysis}

The theory and hypothesis above indicate a relationship between the development of regional growth centres and regional economic growth and inequality. Regional growth centres are regarded as a dynamic function for promoting regional growth and reducing regional inequality. In order to apply these relations, this study sets up a multiple regression model as shown in Equation 6:

$$
\begin{aligned}
G R_{i t}= & a_{1}+b_{1} U R B_{j t}+b_{2} G R P C_{j t}+b_{3} A R G_{j t}+b_{4} M A N_{j t}+ \\
& b_{5} T R A D_{j t}+b_{6} T R A N_{j t}+b_{7} I N V_{j t}+ \\
& b_{8} L O A_{j t}+b_{9} U N I_{j t}+u_{i}
\end{aligned}
$$

Where

$i=$ sub-region $i$

$j=$ regional growth centre $j$

$t=$ period of study, 1987-2007

$u_{i}=$ random error term

$a_{1}=$ constant

$b_{n}=$ regression coefficient, $(n=1, \ldots, 9)$

$G_{i t}^{n}=$ economic growth

$U R B_{j t}=$ urbanisation rate

$G R P^{j t} C_{j t}=$ growth rate of per capita gross growth centre product

$A G R_{i t}=$ growth rate of agricultural product

$M A N_{i t}=$ growth rate of manufacturing product

$T R A D_{j t}=$ growth rate of trade volume

$\operatorname{TRAN}_{j t}{ }^{t}=$ growth rate of transportation product

$I N V_{j t}=$ growth rate of industrial investment

$L O A_{j t}=$ growth rate of loans granted by commercial banks

$U N I_{j t}=$ number of institutes of higher education
This model presents the general growth equation, in which the growth of the sub-regional economy is defined by various factors. However, in this study the growth pole theory is a conceptual framework, and so nine independent variables were defined that can express the developments of regional growth centres. One of the main concepts of the growth pole is urban-based development, and so the urbanisation rate can

\begin{tabular}{|c|c|}
\hline Category & Variable \\
\hline \multirow{7}{*}{$\begin{array}{l}\text { Physical and } \\
\text { infrastructure } \\
\text { (7 variables) }\end{array}$} & Urban area \\
\hline & Regional percentage of urban area \\
\hline & Regional percentage of industrial area \\
\hline & Regional percentage of road length \\
\hline & Regional percentage of electricity consumption \\
\hline & Regional percentage of water consumption \\
\hline & Regional percentage of vehicles registered \\
\hline \multirow{7}{*}{$\begin{array}{l}\text { Population and } \\
\text { labour } \\
\text { (7 variables) }\end{array}$} & Population \\
\hline & Population density \\
\hline & Urban population \\
\hline & Regional percentage of urban population \\
\hline & Provincial percentage of employed labour force \\
\hline & $\begin{array}{l}\text { Provincial percentage of employed industrial } \\
\text { labour force }\end{array}$ \\
\hline & $\begin{array}{l}\text { Provincial percentage of employed services } \\
\text { labour force }\end{array}$ \\
\hline \multirow{10}{*}{$\begin{array}{l}\text { Economy } \\
\text { (11 variables) }\end{array}$} & Regional percentage of GPP per capita \\
\hline & Regional percentage of GPP in industrial sector \\
\hline & Regional percentage of GPP in service sector \\
\hline & Regional percentage of factories \\
\hline & Regional percentage of industrial capital \\
\hline & Regional percentage of businesses \\
\hline & Regional percentage of budgets \\
\hline & Regional percentage of revenue tax \\
\hline & Regional percentage of deposits \\
\hline & Regional percentage of loans \\
\hline \multirow{5}{*}{$\begin{array}{l}\text { Public } \\
\text { services } \\
\text { (5 variables) }\end{array}$} & Number of higher education institutes \\
\hline & $\begin{array}{l}\text { Regional percentage of higher-educated } \\
\text { persons }\end{array}$ \\
\hline & $\begin{array}{l}\text { Regional percentage of high-school-educated } \\
\text { persons }\end{array}$ \\
\hline & Number of medical establishments with beds \\
\hline & Population per medical personnel \\
\hline
\end{tabular}
potentially represent the "urban role" of each regional growth centre. The growth rate of gross regional growth centres' prod-

Table 1: Variables for urban ranking.

Note: Data in 2007 are collected for variables. 
uct per capita is added to investigate the purchasing power of the growth centres, which expresses the level of economic exchange in the area. This also involves another factor: trade volume. Agricultural development still plays an important role in the Northeastern region and some of its products are raw materials for agriculture or the food industry in the urban area. Furthermore, industrial development is a significant factor of the growth pole and should influence the regional growth rate. Thus, the manufacturing product, industrial investment and involved factors, transportation product and loans granted also enter into the equation. The last variable, the number of institutes of higher education, represents the human capital level and knowledge spill-over.

\section{Result and discussion}

\subsection{National and regional growth and inequality}

During the period of the study, Thailand was a fast-growing nation, evidenced by a high annual growth rate of real GDP. However, over this long period, there were several economic situations: from the miracle years in the first decade, to the crisis in 1997, to the recovery in the later years. The first part of study period (1987-1996) was the miracle growth time, at approximately $9.50 \%$ per year. It reached a peak in 1988 at $13.29 \%$. Unexpectedly, the economic crisis struck in the first year of the second decade, in 1997. Growth fell to its lowest at $-10.51 \%$ the following year. After the shock, from 1999 to 2007, growth quietly recovered with an annual average of $5.05 \%$. Thus, from 1987 to 2007, the annual average rate of growth was $5.81 \%$.

The regional growth trend seems to match the national level. There are two remarkable growth regions that exceed the national growth rate: the Eastern region (at an annual average of 9.02\%) and the Central region (at an annual average of 7.54\%).

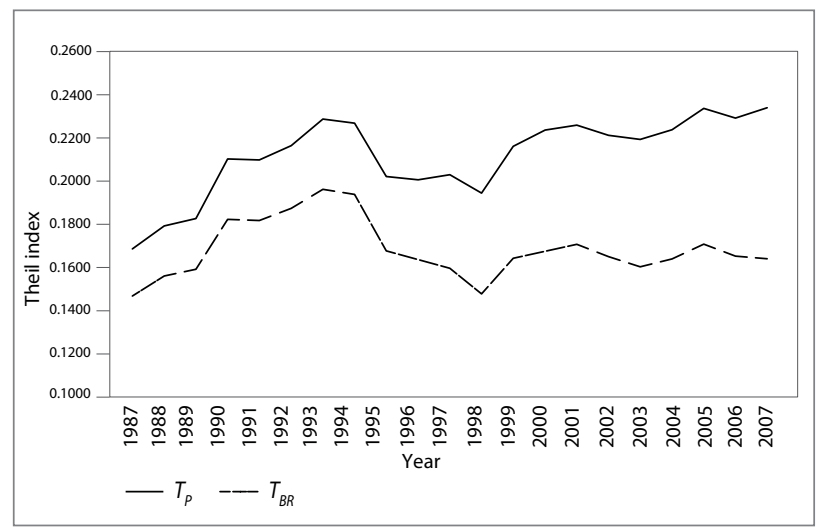

Figure 4: Overall inequality $\left(T_{P}\right)$ and between-region inequality $\left(T_{B R}\right)$ (source: Office of the National Economic and Social Development Board, 2011).

Note: Calculated from gross domestic, regional and provincial product; $T_{P}=$ overall inequality and $T_{B R}=$ between-region inequality.
Industrialisation is presumably driving their growth. The positions of other regions are the Bangkok metropolitan region at $5.38 \%$, the Southern region at $5.21 \%$, the Northeastern region at $4.49 \%$ and the Northern region at $4.03 \%$.

Referring to the national and regional inequality in Figure 4, the trend of overall inequality $\left(T_{p}\right)$ increased throughout the study period by annual average of $1.65 \%$. This result is related to what other studies have also found (e.g. Nopkhun, 2005; Boonyamanond, 2007; Wisaweisun, 2009). This trend matches between-region inequality $\left(T_{B R}\right)$ and has not increased much, at an annual average of only $0.56 \%$. These rates were at the bottom in the early years and during the shock of the economic crisis. Thus, all along Thailand has experienced spatial economic inequality, especially during the miracle growth and recovery phases. The inequality rate was particularly affected during the crisis. In sum, higher economic growth over the past twenty years contributed to higher income but did not spread across any region, and regions with higher growth were more sensitive to the economic crisis than other regions. The space between the two lines is within-region inequality $\left(T_{W R}\right)$, which increased during the time. This situation is illustrated in Figure 5, showing the relative contribution of the Theil index. The upper line, $T_{B R}$, has fallen significantly, whereas the lower line, $T_{W R}$, has risen. Based on this evidence, regional decentralisation in modern Thailand's development works effectively because of the decreasing $T_{B R}$. Not only the Bangkok metropolitan region, as the peak region of the nation, but also other regions, particularly the Eastern and Central regions, gain the benefits of national growth. However, at the same time, this success has side effects; there is more within-region inequality in each region. Thus, although the national economy grew, such growth was limited to only a few areas of the regions. Thailand therefore has a new inequality dilemma: within-region inequality.

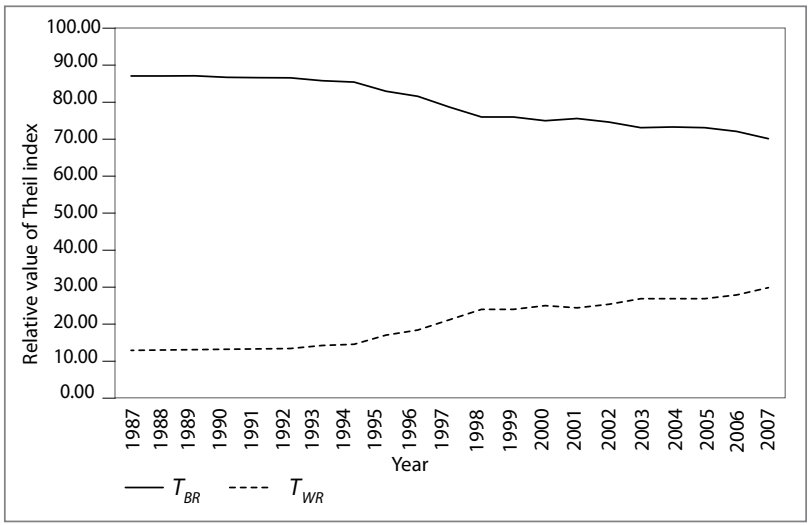

Figure 5: Relative value of the Theil index (source: Office of the National Economic and Social Development Board, 2011).

Note: Calculated from gross domestic, regional and provincial product; $T_{B R}=$ between-region inequality and $T_{W R}=$ within-region inequality. 
In Figure 6, within-region inequality is obviously higher for the Group A region (represented by the indexes of the Bangkok metropolitan region, Central region and Eastern region) than the Group B region (the Northeastern region, Northern region and Southern region). It has already been noted that the economic growth of the Group A region is also absolutely higher than the Group B region. This is clear not only at the national level, which faces within-region inequality, but also at the regional level, particularly in high-growth regions. This evidence shows that economic growth is not spatially apparent overall. Only some areas in each region gain the benefit of economic growth: presumably urban areas or industrial zones.

\subsection{Regional growth centres and sub-regions}

The result of urban ranking is shown in Figure 7. The scores for Nakhon Ratchasima, Khon Kaen, Udon Thani and Ubon Ratchathani stand out, and point A in Figure 7 is the sharp curve point, which separates the graph into two parts as follows:

1. Group 1: the top four provinces are Nakhon Ratchasima, Khon Kaen, Udon Thani and Ubon Ratchathani. They are identified as regional growth centres.

2. Group 2: the remainder consists of Buri Ram, Surin, Roi Et, Kalasin, Sakon Nakhon, Chaiyaphum, Si Sa Ket, Maha Sarakham, Nong Khai, Loei, Nakhon Phanom, Nong Bua Lam Phu, Mukdahan, Yasothon and Amnat Charoen. They are identified as satellite towns.

Figure 8 describes spatial interaction between Group 1 and Group 2. Thus there are four sub-regions (by the number of regional growth centres). Their details are as follows:

1. The Upper Northeastern sub-region (UNESR)

Udon Thani is the growth centre and its satellite towns are Loei, Nong Khai, Sakon Nakhon and Nong Bua Lam Phu.

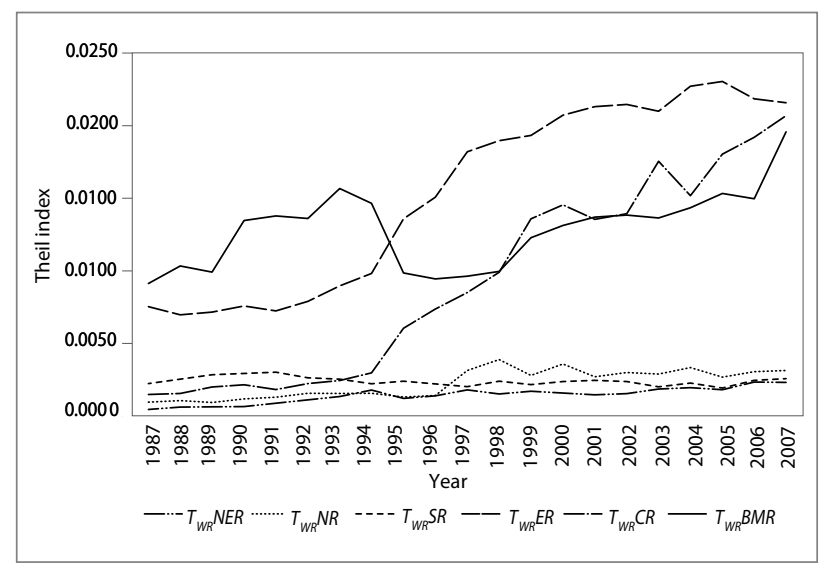

Figure 6: Within-region inequality $\left(T_{W R}\right)$ (source: Office of the National Economic and Social Development Board, 2011).

Note: Calculated from gross domestic, regional and provincial product; $\mathrm{NER}=$ Northeastern region, $\mathrm{NR}=$ Northern region, $\mathrm{SR}=$ Southern region, $\mathrm{ER}=$ Eastern region, $\mathrm{CR}=$ Central region and $\mathrm{BMR}=$ Bangkok metropolitan region.
This sub-region covers $43,852.044 \mathrm{~km}^{2}$ and had a population of 4,659,509 in 2007. In economic terms, the gross sub-regional product (GSRP) in 2007 was THB 83.6 billion (about USD 2.7 billion). This volume represents 19.1\% in the agricultural sector, $17.5 \%$ in the industrial sector and $63.4 \%$ in the service sector, with an average annual growth rate of $4.05 \%$ from 1987 to 2007. Udon Thani, as the growth centre, has a population of 1,530,686 and so it is the sixth-largest province in Thailand. Its GPP is THB 31.8 billion (about USD 1.0 billion) and most of it is from the service sector.

2. The Central Northeastern sub-region (CNESR)

Khon Kaen is the growth centre and its satellite towns are Kalasin, Roi Et, Maha Sarakham and Nakhon Phanom. This sub-region covers $36,936.537 \mathrm{~km}^{2}$ and had a population of 5,671,621 in 2007. In economic terms, the GSRP in 2007 was THB 135.4 billion (about USD 4.4 billion). It is the largest sub-region in terms of economic size. This volume represents $15.4 \%$ in the agricultural sector, $34.7 \%$ in the industrial sector and $49.9 \%$ in the service sector, and had an average annual growth rate of 5.23\% from 1987 to 2007. Khon Kaen, as the growth centre, has a population of $1,752,414$ and so it is the fourth-largest province in Thailand. Its GPP is THB 70.0 billion (about USD 2.3 billion) and most of it is from the industrial sector.

3. The Lower Northeastern sub-region 1 (LNSR 1)

Nakhon Ratchasima is the growth centre and its satellite towns are Buri Ram, Chaiyaphum and Surin. This sub-region is the largest sub-region, covering $51,719.192 \mathrm{~km}^{2}$ and with a population of 6,581,233 in 2007. In economic terms, the GSRP in 2007 was THB 133.5 billion (about USD 4.3 billion). This volume represents $21.0 \%$ in the agricultural sector, $25.4 \%$ in the industrial sector and $53.6 \%$ in the service sector and with an average annual growth

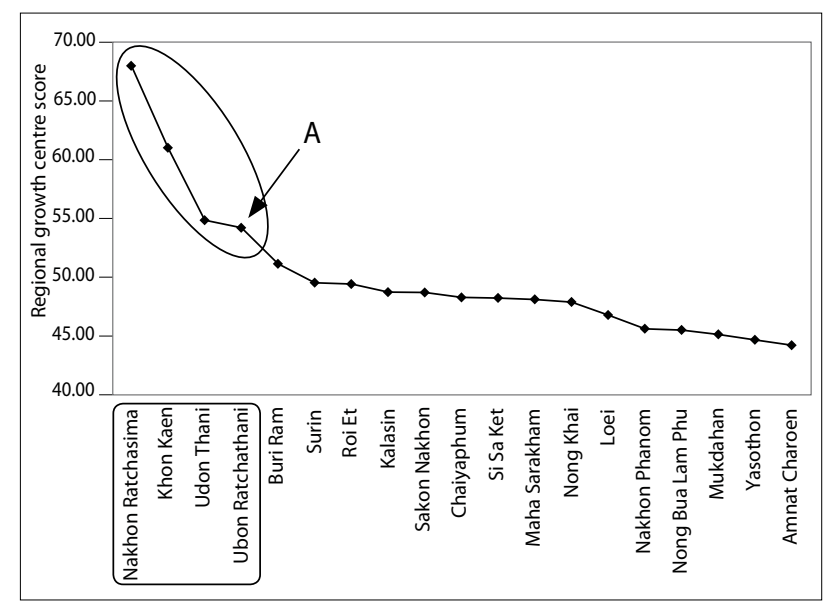

Figure 7: Result of urban ranking.

Note: The calculation from the Z-score regression is used as Equation 4; point $A$ is the sharp curve point, which separates the graph into two parts. 
rate of 4.39\% from 1987 to 2007. Nakhon Ratchasima, as the growth centre, has a population of 2,552,894 and so it is the second-largest province in Thailand. Its GPP is THB 68.9 billion (about USD 2.2 billion) and most of it is from the service sector.

4. The Lower Northeastern sub-region 2 (LNSR 2)

Ubon Ratchathani is the growth centre and its satellite towns are Mukdahan, Si Sa Ket, Amnat Charoen and Yasothon. This sub-region covers $36,624.331 \mathrm{~km}^{2}$ and had a population of 4,473,284 in 2007. In economic terms, GSRP in 2007 was THB 72.6 billion (about USD 2.3 billion). This volume represents $21.2 \%$ in the agricultural sector, $14.1 \%$ in the industrial sector and $64.7 \%$ in the service sector, and had an average annual growth rate of 3.95\% from 1987 to 2007. Ubon Ratchathani, as the growth centre, has a pop- ulation of $1,785,709$ and so it is the third-largest province in Thailand. Its GPP is THB 31.8 billion (about USD 1.0 billion) and most of it is from the service sector.

Most of sub-regions' economies are based on the service sector, except for the Central Northeastern sub-region. Khon Kaen is the only industrial growth centre. Analysis of the sub-regions in the Northeastern region shows that the highest economic growth is in the Central Northeastern sub-region, at an annual average of $5.23 \%$ (more than the growth rate of the Northeastern region). The positions of the other sub-regions are the Lower Northeastern sub-region 1 at 4.39\%, the Upper Northeastern sub-region at $4.03 \%$ and the Lower Northeastern sub-region 2 at $3.95 \%$.

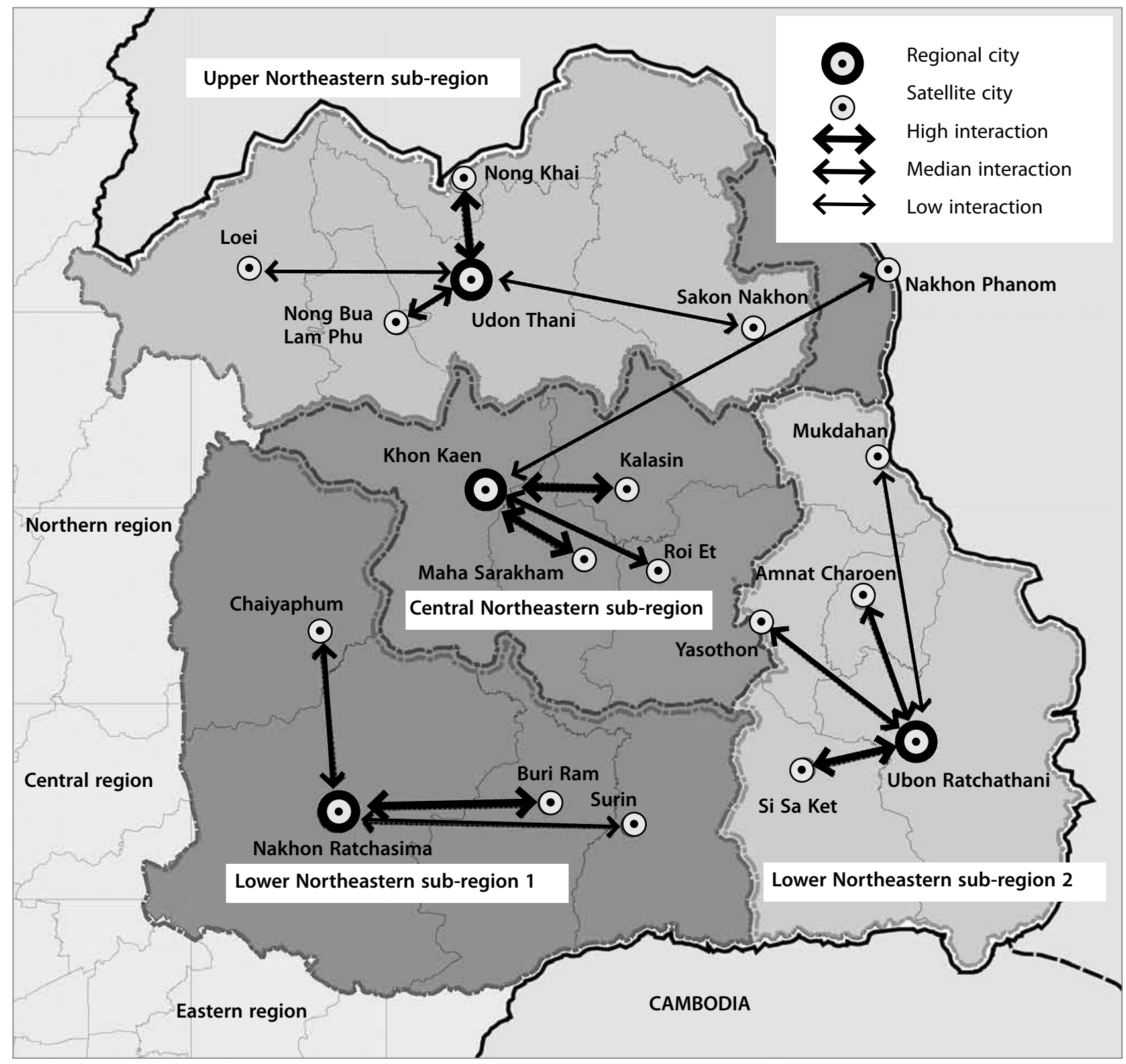

Figure 8: Sub-regions (source: Sang-arun, 2012). 
Figure 9 shows regional inequality. The trends of both overall inequality $\left(T_{P}\right)$ and between-sub-regional inequalities $\left(T_{B S R}\right)$ increased throughout the time of the study. $T_{p}$ has excessively increased. Moreover, the space between these lines is widely separated from each other because of within-sub-region inequality, as shown in Figure 10. The indexes of the Central Northeastern sub-region and Lower Northeastern sub-region 1 (referred to as Group C) are obviously higher than the Upper Northeastern sub-region and the Lower Northeastern sub-region 2 (referred to as Group D). As already mentioned, the economic growth of Group $\mathrm{C}$ is also absolutely higher than Group D. Thus the higher growth during this period did not spread across any sub-regions.

\subsection{Impact of regional growth centre development on regional growth}

The findings for each category yield a regression coefficient, $R^{2}, t$-statistic, $F$-statistic and probabilities for regression models on the impact of regional growth centre development on regional growth. $R^{2}$ assesses the predictive power of the set of independent variables on regional growth, and the coefficient is the unique predictive power of each variable.

\subsubsection{Upper Northeastern sub-region}

The findings for this sub-region are presented in Table 2. All aspects of Udon Thani, except for industrial investment and the number of higher education institutes, were statistically significant. The results show that the growth rate of gross product per capita and the urbanisation rate are important factors for sub-region growth. The sign of all coefficients is plus $(+)$, except for the transportation product volume. This shows that the development of the Udon Thani growth centre

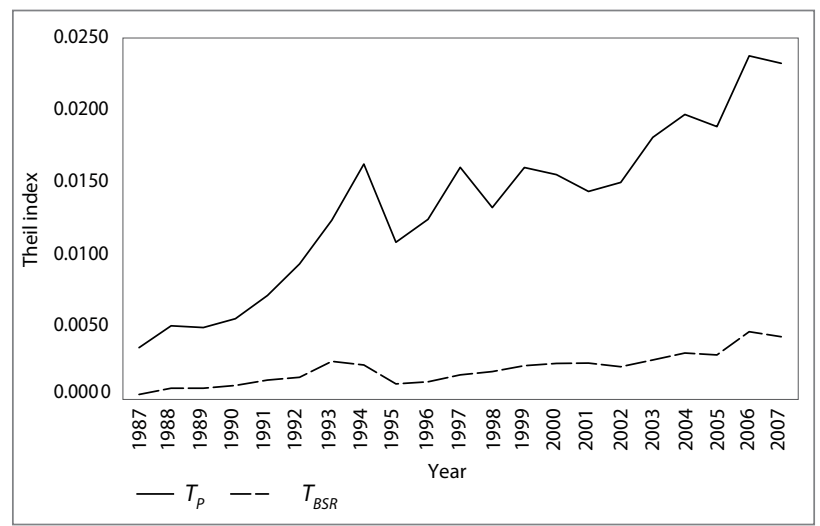

Figure 9: Overall inequality $\left(T_{p}\right)$ and between-sub-regional inequality $\left(T_{B S R}\right)$ (source: Office of the National Economic and Social Development Board, 2011).

Note: Calculated from gross domestic, regional and provincial product; $T_{P}=$ overall inequality and $T_{B S R}=$ between-sub-regional inequality. has the same direction as the growth of the sub-region. Based on these findings, Udon Thani's purchasing power measured by annual per capita GPP growth rate, urbanisation and the growth rate of trade volume are most directly correlated to the growth of the sub-region. The result corresponds to the service sector economic base of Udon Thani. It is possible to design the development policy for this sub-region by promoting these factors and also by improving other factors, especially industry and transportation. Moreover, the spatial potential of the sub-region is the border area, which is directly connected to Vientiane, the capital of Laos. Export-oriented industrial development should be promoted for this sub-region.

\subsubsection{Central Northeastern sub-region}

The findings for this sub-region are presented in Table 3. All aspects of Khon Kaen's development, except for the growth rate of loans granted by commercial banks, were statistically significant. The findings reveal that the urbanisation rate and growth rate of gross product per capita are important factors for sub-region growth. The sign of most coefficients is plus (+). This shows that the development of Khon Kaen has the same direction as the growth of the sub-region. Based on these findings, Khon Kaen's urbanisation, the purchasing power measured by annual per capita GPP growth rate and the growth rate of agricultural volume are the most directly correlated to the growth of the sub-region. However, industrial factors have only a slight impact on this growth, even if Khon Kaen is the only growth centre based on an industrial economy. It shows that the industrial development of Khon Kaen is not linked to the industry of its satellite towns. Thus, developing industrial links between Khon Kaen and its satellite towns should be the main policy.

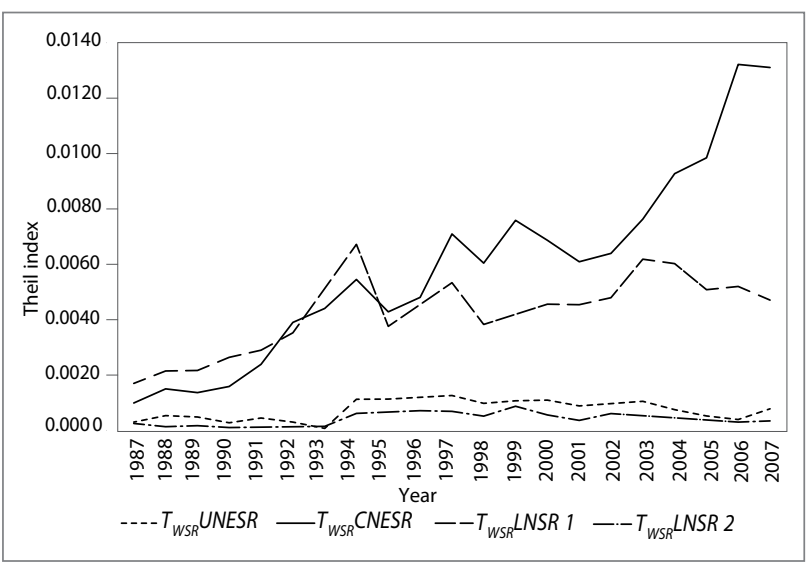

Figure 10: Within-sub-region inequality $\left(T_{\text {WSR }}\right)$ (source: Office of the National Economic and Social Development Board, 2011).

Note: Calculated from gross domestic, regional and provincial product; UNESR = Upper Northeastern sub-region, CNESR = Central Northeastern sub-region, LNESR 1 = Lower Northeastern sub-region 1 and LNESR 2 = Lower Northeastern sub-region 2. 
Table 2: Regression results for the Upper Northeastern sub-region model.

\begin{tabular}{|c|c|c|c|}
\hline \multicolumn{4}{|c|}{ Dependent variable: $G R_{i t}$} \\
\hline Independent variable & Coefficient & $t$-statistic & Probability \\
\hline constant & -0.977272 & -0.689964 & 0.5023 \\
\hline$U R B_{j t}$ & 0.140487 & 1.795415 & $0.0959 * *$ \\
\hline$G R P C_{j t}$ & 0.563848 & 6.616486 & $0.0000^{*}$ \\
\hline$A G R_{j t}$ & 0.083692 & 2.103003 & $0.0555^{* *}$ \\
\hline$M A N_{j t}$ & 0.048633 & 1.428097 & $0.1768^{* * *}$ \\
\hline$T R A D_{j t}$ & 0.085936 & 1.782901 & $0.0980^{* *}$ \\
\hline $\operatorname{TRAN}_{j t}$ & -0.001993 & -1.371473 & $0.1934^{* * *}$ \\
\hline \multicolumn{4}{|l|}{$I N V_{j t}$} \\
\hline$L O A_{j t}$ & 0.020708 & 1.279176 & $0.2232^{* * *}$ \\
\hline \multicolumn{4}{|l|}{$U N I_{j t}$} \\
\hline$R^{2}=0.941239 ; F$-statis & istic) $=0.0$ & & \\
\hline
\end{tabular}

Note: $\left.\left(^{*}\right),{ }^{* *}\right)$ and $\left(^{* * *}\right)$ signify statistical significance at the $0.01,0.10$ and 0.20 levels; the independent variable $\operatorname{TRAN}_{j t}$ (transportation product volume) may be different from the variable mentioned in section 2.3; there is no statistical significance for $I N V_{j t}$ and $U N I_{j t}$

Table 3: Regression results for the Central Northeastern sub-region model.

\begin{tabular}{llll}
\hline Dependent variable: $G R_{i t}$ & & \\
\hline Independent variable & Coefficient & -statistic & Probability \\
\hline constant & 18.36988 & 2.910001 & 0.0131 \\
\hline$U R B_{j t}$ & 0.320150 & 2.830178 & $0.0152^{* *}$ \\
\hline$G R P C_{j t}$ & 0.177264 & 1.633023 & $0.1284^{* * *}$ \\
\hline$A G R_{j t}$ & 0.147627 & 3.714547 & $0.0030^{*}$ \\
\hline$M A N_{j t}$ & 0.057473 & 2.315967 & $0.0391^{* *}$ \\
\hline$T R A D_{j t}$ & 0.131304 & 4.117769 & $0.0014^{*}$ \\
\hline$T R A N_{j t}$ & -2.632152 & -3.701508 & $0.0030^{*}$ \\
\hline$I N V_{j t}$ & -0.117191 & -2.836449 & $0.0150^{* *}$ \\
\hline$L O A_{j t}$ & & & $0.1287^{* * *}$ \\
\hline$U N I_{j t}^{*}$ & -1.138338 & -1.631862 &
\end{tabular}

$R^{2}=0.953642 ;$ F-statistic $=30.85697 ; p$ (F-statistic) $=0.00000$

Note: $\left.\left({ }^{*}\right),{ }^{* *}\right)$ and $\left(^{* * *}\right)$ signify statistical significance at the $0.01,0.10$ and 0.20 levels; the independent variable $\operatorname{TRAN}_{j \mathrm{t}}$ (transportation product as a percentage of real gross regional growth centre product) may be different from the variable mentioned in section 2.3; there is no statistical significance for $L O A_{j t}$

Table 4: Regression results for the Lower Northeastern sub-region 1 model.

\begin{tabular}{lccl}
\hline Dependent variable: $G R_{i t}$ & & \\
\hline Independent variable & Coefficient & $t$-statistic & Probability \\
\hline constant & -14.15167 & -3.534184 & 0.0041 \\
\hline$U R B_{j t}$ & 0.207815 & 1.619519 & $0.1313^{* * *}$ \\
\hline$G R P C_{j t}$ & 0.177058 & 1.507416 & $0.1576^{* * *}$ \\
\hline$A G R_{j t}$ & 0.176278 & 4.253901 & $0.0011^{*}$ \\
\hline$M A N_{j t}$ & 0.071064 & 2.667839 & $0.0205^{* *}$ \\
\hline$T R A D_{j t}$ & 0.135486 & 3.197426 & $0.0077^{*}$ \\
\hline$T R A N_{j t}$ & & & $0.0196^{* *}$ \\
\hline$I N V_{j t}$ & -0.098640 & -2.691138 & $0.0350^{* *}$ \\
\hline$U O A_{j t}$ & 0.115277 & 2.376101 & $0.0071^{*}$
\end{tabular}

$R^{2}=0.969475 ; F$-statistic $=47.64066 ; p(F$-statistic $)=0.00000$

Note: $\left({ }^{*}\right),\left(^{* *}\right)$ and $\left({ }^{* *}\right)$ signify statistical significance at the $0.01,0.10$ and 0.20 levels; the independent variable $I N V_{j t}$ (industrial investment as a percentage of real gross regional growth centre product) may be different from the variable mentioned in section 2.3 ; there is no statistical significance for $\operatorname{TRAN}_{j t^{*}}$ 
Table 5: Regression results for the Lower Northeastern sub-region 2 model.

\begin{tabular}{lccl}
\hline Dependent variable: $G R_{i t}$ & & \\
\hline Independent variable & Coefficient & $t$-statistic & Probability \\
\hline constant & -4.941407 & -5.101931 & 0.0002 \\
\hline$U R B_{j t}$ & & & \\
\hline$G R P C_{j t}$ & 0.395837 & 14.45285 & $0.0000^{*}$ \\
\hline$A G R_{j t}$ & 0.140841 & 9.064837 & $0.0000^{*}$ \\
\hline$M A N_{j t}$ & & & $0.0000^{*}$ \\
\hline$T R A D_{j t}$ & 0.241668 & 11.90070 & $0.0336^{* *}$ \\
\hline$T R A N_{j t}$ & -0.741904 & -2.375647 & $0.0350^{* *}$ \\
\hline$I N V_{j t}$ & 0.019072 & 2.353492 & $0.0006^{*}$ \\
\hline$L O A_{j t}$ & -0.042014 & -4.529871 & $0.0002^{*}$
\end{tabular}

$R^{2}=0.988847 ; F$-statistic $=164.6548 ; p(F$-statistic $)=0.00000$

Note: $\left.\left({ }^{*}\right),{ }^{* *}\right)$ and $\left(^{* * *}\right)$ signify statistical significance at the $0.01,0.10$ and 0.20 levels; the independent variables $\operatorname{TRAN}_{j t}$ (transportation product as a percentage of real gross regional growth centre product) and $L O A_{j t}$ (loans granted by commercial banks as a percentage of real gross regional growth centre product) may be different from the variables mentioned in section 2.3; there is no statistical significance for $U R B_{j t}$ and $M A N_{j t}$

\subsubsection{Lower Northeastern sub-region 1}

The findings for this sub-region are presented in Table 4. All aspects of Nakhon Ratchasima's development, except for transportation product, were statistically significant. The findings show that number of higher education institutes and the urbanisation rate are important factors for sub-region growth. The sign of all coefficients is plus (+), except for industrial investment. This shows that the development of Nakhon Ratchasima has the same direction as the growth of the sub-region. Based on these findings, Nakhon Ratchasima's education measured by the number of higher educational institutes, urbanisation and purchasing power are most directly correlated to the growth of the sub-region. It is not surprising that education plays the main role for sub-regional development because Nakhon Ratchasima is the educational centre of the Northeastern region. Therefore linking higher education and sub-region development, especially industry and related sectors, should be a strong policy.

\subsubsection{Lower Northeastern sub-region 2}

The findings for this sub-region are presented in Table 5. All aspects of Ubon Ratchathani's development, except for the urbanisation rate and growth rate of manufacturing product, were statistically significant. The findings show that number of higher education institutes and the growth rate of gross product per capita are important factors for sub-region growth. The sign of most coefficients is plus (+). This shows that the development of Ubon Ratchathani has the same direction as the growth of the sub-region. The findings show that Ubon Ratchathani's education, purchasing power and growth rate of trade volume are most directly correlated. This corresponds to the service sector economic base of Ubon Ratchathani and the sub-region.

\section{Conclusion}

The impact of regional growth centres as a driver of (sub)-regional growth is analysed using the least squares estimation method of regression. Most factors of regional growth centre development correlate positively with the growth of the sub-region. In the case of the Upper Northeastern sub-region, the most important factor is people's purchasing power. For the Central Northeastern sub-region, the most important factor is the urbanisation rate. For the Lower Northeastern sub-region 1, the number of higher education institutes is the most influential for growth. For the Lower Northeastern sub-region 2, the number of higher educational institutes seems to be an important factor for sub-region growth. When considered in conjunction with the inequality of each sub-region, it is found that all sub-regions have a tendency toward increasing inequality, especially in the Central Northeastern sub-region and the Lower Northeastern sub-region 1. From the results of the analysis, it is shown that the development of the growth centres has an impact on sub-regional growth but that this economic growth does not reduce inequality, as seen in the Central Northeastern sub-region and Lower Northeastern sub-region 1 . The sub-regions with a high rate of economic growth absolutely have extensive within-sub-region inequality. It may be concluded that the spatial development of regional growth centres during the past period has resulted in positive economic growth, but that this growth has not spread evenly. The current effect is lingering inequality. This is inconsistent with the theory and policy framework that has been implemented.

This study suggests that at the national level regional decentralisation policies are an important policy in Thailand, but more strategy is needed. It is not necessary to abandon the 
growth centre strategy, but it should be improved by promoting more economic links between regional growth centres and their satellite towns, and also areas with greater potential. The government should design specific policies for the regions lagging behind the most: the Northeastern region and the Northern region. These new policies should be based on the spatial potentials of each region. Furthermore, within-region inequality should be carefully and urgently considered. Balanced policies are required for all development prospects. These balances include not only balance among economic sectors, but also spatial and social balance. For the Northeastern region, the recommendation includes economic links between regional growth centres and their satellite towns. However, each sub-region should have its own specific policy. Linking trade and other service sectors should be the primary policy for the Upper Northeastern sub-region and the Lower Northeastern sub-region 2. Industrial links should be created for the Central Northeastern sub-region and the Lower Northeastern sub-region 1. Moreover, policymakers should identify all sub-regions where improvement of transportation and other infrastructure is necessary and should secure investment opportunities and loans. Such a strong process will spread the growth of regional growth centres and lead to the development of surrounding areas.

Nattapon Sang-arun

Thammsat University, College of Interdisciplinary Studies, Bangkok, Thailand

E-mail: nattapon_s@aol.com

\section{Notes}

${ }^{[1]} \mathrm{THB}=$ Thai baht.

[2] There are 19 provinces in the Northeastern region: Khon Kaen, Udon Thani, Loei, Nong Khai, Mukdahan, Nakhon Phanom, Sakon Nakhon, Kalasin, Nakhon Ratchasima, Chaiyaphum, Yasothon, Ubon Ratchathani, Roi Et, Buri Ram, Surin, Maha Sarakham, Si Sa Ket, Nong Bua Lam Phu and Amnat Charoen.

\section{Acknowledgements}

This study received financial support from the Faculty Development Scholarships, Office of the Higher Education Commission of Thailand. The author thanks Pranee Tinakorn and Suwattana Thadaniti for their advice.

\section{References}

Akita, T. (2000) Decomposing regional income inequality using two-stage nested Theil decomposition method. Paper presented at the 6th World Congress of the Regional Science Association International, 16-20 May, Lugano, Switzerland. Typescript.

Barcelona Field Studies Centre. (2011) Core - periphery model. Available at: http://www.geographyfieldwork.com (accessed 15 Mar. 2011).
Boonyamanond, S. (2007) Interconnection between income distribution and economic growth: Cross-country and Thai evidence. Doctoral thesis. Bangkok, Chulalongkorn University, Faculty of Economics.

Boudeville, J. R. (1966) Problems of regional economic planning. Edinburgh, Edinburgh University Press.

Darwent, D. F. (1969) Growth poles and growth centres in regional planning: A review. Environment and Planning, 1(1), pp. 5-32. DOI: 10.1068/a010005

Deolalikar, A. B. (2002) Poverty, growth and inequality in Thailand. Manila, Asian Development Bank.

Glassman, J. \& Sneddon, C. (2003) Chiang Mai and Khon Kaen as growth poles: Regional industrial development in Thailand and its implications for Urban Sustainability. The Annals of the American Academy of Political and Social Science, 590, pp. 93-115. DOI: $10.1177 / 0002716203257075$

Hirschman, A. O. (1958) The strategy of economic development. New Haven, Yale University Press.

Ikemoto, Y. \& Limskul, K. (1987) Income inequality and regional disparity in Thailand, 1962-81. The developing economies, 25(3), pp. 249-269. DOI: 10.1111/j.1746-1049.1987.tb00109.x

Kaothien, U. (1991) Regional and urbanisation policy in Thailand: The tertiary sector as a leading sector in regional development. Urban Studies, 28(6), pp. 1027-1043. DOI: 10.1080/00420989120081181

Malul, M., Rosenboim, M. \& Shavit, T. (2012) Misleading perceptions and economic efficiency in a regional system. Urbani izziv, 23(2), pp. 131139. DOI: 10.5379/urbani-izziv-en-2012-23-02-006

National Economic and Social Development Board (1987) The sixth national economic and social development plan (1987-1991). Bangkok, Office of the Prime Minister.

Nopkhun, T. (2005) Globalization, growth and regional disparity: Testing Thailand's experience 1981-2003. Doctoral thesis. Dekalb, Northern Illinois University, Department of Economics.

Office of the National Economic and Social Development Board (2011) Gross regional and provincial product. Available at: http://www.nesdb. go.th. (accessed 15 Mar. 2011).

Perroux, F. (1955) Note on the concept of growth poles. In: David L. M., Robert D. D. \& William H. L. (eds.) Regional economics: Theory and practice, pp. 93-104. New York, The Free Press.

Sandberg, K. \& Meijers, E. (2006) Polycentric development to combat regional disparities? The relation between polycentricity and regional disparities in European countries. Proceedings of the 46th Congress of the European Regional Science Association, pp. 1-20. Volos, University of Thessaly.

Sang-arun, N. (2012) Development of regional growth centers and impact on regional growth: Case study of Thailand's Northeastern region. Doctoral thesis. Bangkok, Thammasat University, College of Interdisciplinary Studies.

Tinakorn, P. (2002) Income inequality in four decades of development: 1961-2001. Thammasat Economic Journal, 20(2-3), pp. 141-208.

Wisaweisun, N. (2009) Spatial disparities in Thailand: Does government policy aggravate or alleviate the problem? In: Huang, Y. \& Bocchi, M. B. (eds.) Reshaping economic geography in East Asia, pp. 184-194. Washington, DC, The World Bank. 